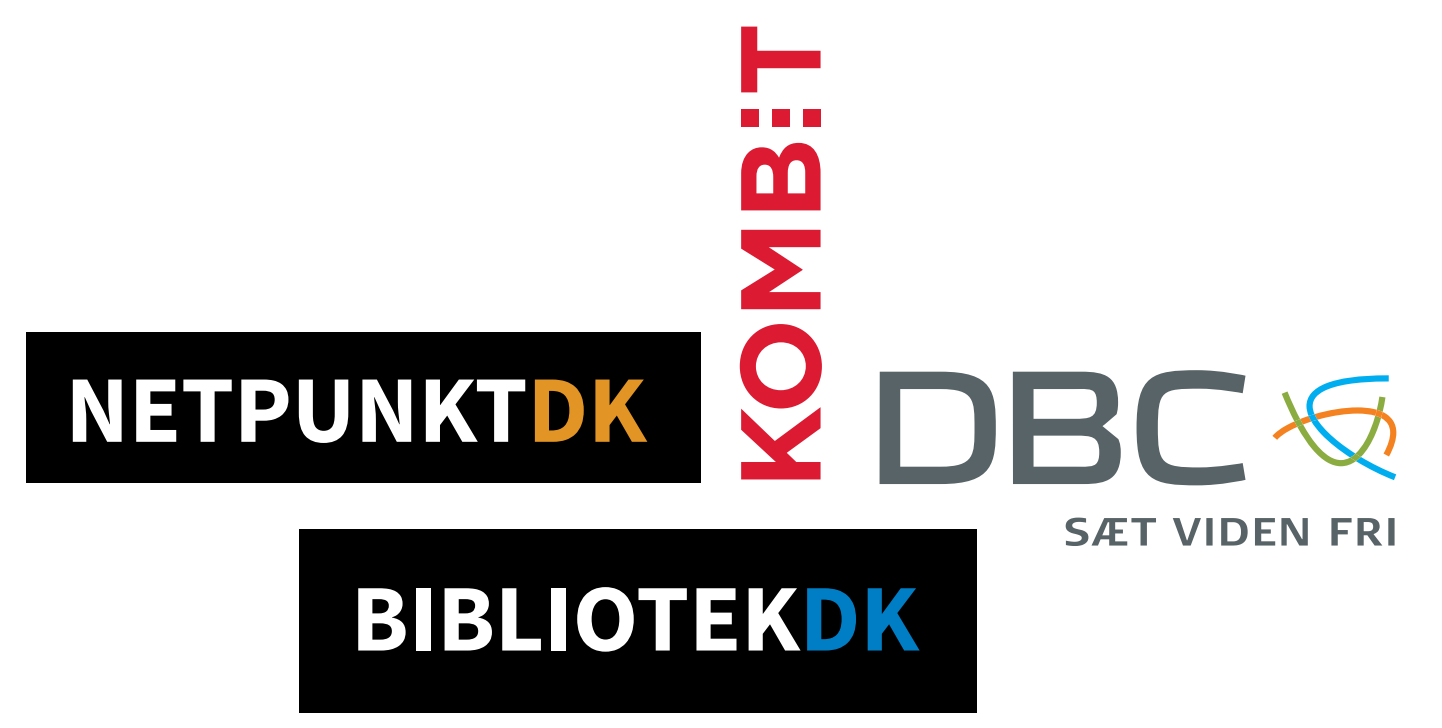

\title{
DBC og den nationale \\ biblioteksinfrastruktur på kommunale hænder
}

\author{
"Med det nye paradigme bliver DBC underlagt en \\ strammere styring. Det rummer i sagens natur en risiko \\ for en mindre fleksibilitet, men kan måske også sikre \\ en større indflydelse til bibliotekerne."
}

Af Leif Andresen, Chefkonsulent,

leif@kb.dk

DOI: 10.22439/revy.v43i2.5998

Efter længere tids forberedelser og langstrakte forhandlinger mellem Kulturministeriet og Kommunernes Landsforening $(K L)$ overgik det fulde ejerskab til DBC til KL pr. 1. januar 2020 inkl. alle DBCs nationale opgaver. Kommunernes it-fællesskab (KOMBIT) er bestiller for alle disse opgaver.

\section{Forhistorien til 2019}

Oprindelig var der ikke én national fælleskatalog, men to: én for folkebibliotekerne og én for forskningsbibliotekerne.
Folkebibliotekernes BASIS var en videreudvikling af Bibliotekscentralens produktion af trykte kort til folkebibliotekerne og registrering af primært bøger til nationalbibliografien. I forbindelse med at folkebibliotekerne i slutningen af 1980'erne / starten af 1990'erne gik fra kortkataloger til edb-kataloger videreudvikledes BASIS til også at fungere som fælleskatalog for folkebibliotekerne. BASIS blev videreført efter Bibliotekscentralens konkurs 1990 som følge af et mislykket mexicansk biblioteksmøbelseven- tyr af DBC - Dansk BiblioteksCenter, der blev etableret med kommunalt ejerskab med deltagelse af Gyldendal.

Forskningsbibliotekernes ALBA / Samkat blev drevet af Forskningsbibliotekerne EDB-kontor, som henhørte under Rigsbibliotekarembedet og efter omlægning til Statens Bibliotekstjeneste indgik som en afdeling i SBT.

Det første skridt til DanBib blev taget på SBTs biblioteksledermøde i 1990, hvor Per Mogens Petersen, daværen- 


\section{Forkortelser og begreber}

- BDI Bibliotekernes Data og It: Kombits overbygning på FBS og FBI

- Bestillerfunktion:"Brobygger" mellem bibliotekerne og it-leverandørerne. Bestilleren påtager sig de planlæggende, rapporterende, faciliterende, formidlende og styrende opgaver, der skal til for at skabe et konstruktivt samarbejde mellem parterne og en effektiv it-drift og -videreudvikling (Kombits definition)

- DDB CMS er folkebibliotekernes fælles hjemmesideplatform, som anvendes af 82 biblioteker. Der er i alt 97 folkebiblioteker.

- DDB Danskernes Digitale Bibliotek: 2012-2020 fælles organisering af folkebibliotekernes digitale udvikling og drift. Fra 2013 også bestillerfunktion på DanBib og bibliotek.dk.

- FBI Fælles Biblioteksinfrastruktur: “databrønden”, DanBib, bibliotek.dk, lånesamarbejdets infrastruktur mv. med DBC som leverandør

- FBS Fælles Bibliotekssystem: folkebibliotekernes fælles system med Systematic som leverandør (brugergrænsefladen er særskilt, se: DDB CMS)

- KOMBIT kommunernes it-fællesskab etableret i 2009 i forbindelse med KLs salg af Kommunedata. Varetager fælleskommunale it-indkøb og it-leverandørstyring. Formålet med etablering af KOMBIT var at bryde med det hidtidige monopol og at etablere et marked for fælleskommunale it-løsninger.

- SBD Supplerende Biblioteksdata; blev tidligere betegnet som Bibliotekskatalogisering.

de leder af Forskningsbibliotekernes EDB-Kontor, foreslog et datafællesskab mellem folke- og forskningsbiblioteker. Det satte gang i en proces, der blev forsinket af Bibliotekscentralens konkurs. I 1993 var en aftale klar og DanBib blev formelt etableret pr. 1. januar 1994.

Formalia var at DBC drev DanBib efter opdrag af Kulturministeriet, KL samt Københavns og Frederiksberg kommuner. Samtidig gik staten ved Kulturministeriet ind i ejerkredsen for DBC A/S, som derefter bestod af KL, Københavns Kommune, Gyldendal og staten ved Kulturministeriet. DanBib-opgaven blev henlagt til DBC af DanBib-opdragsgiverne (staten, KL samt Københavns og Frederiksberg kommuner) med DBCs bestyrelse som det fagligt ansvarlige organ.

Med den nye bibliotekslov fra maj 2000 blev bibliotek.dk etableret og gik i luften i oktober 2000 som en overbygning på DanBib med Biblioteksstyrelsen som bestiller. Siden udgik Københavns Kommune og Gyldendal af DBC's ejerkreds.

Efter etablering af Danskernes Digitale Bibliotek (DDB) ind på banen i 2012 blev det uden sammenhæng med grundlaget for DDB i øvrigt primo 2013 besluttet at opdragsgivermodellen skulle erstattes af DDB som bestiller for DanBib og bibliotek.dk.

\section{Lovændringen forår 2019}

Med virkning fra 1. januar 2020 blev Lov om biblioteksvirksomheds $\$ 16$ om "Statslige og andre tværgående opgaver på biblioteksområdet" ændret til "Øvrige statslige og andre tværgående opgaver på biblioteksområdet”. Dette hænger sammen med statens salg af sine aktier i Dansk BiblioteksCenter (DBC), som fra 1. januar 2020 er $100 \%$ ejet af KL. 
Der var op til Folketingets behandling en høringsrunde. En lang række af høringssvarene fokuserede på forsknings-, fag-og uddannelsesbibliotekernes situation ved overgang til rent kommunalt ejerskab. Dette forhold slog også igennem i folketingets behandling, hvor der bredt blev givet udtryk for at FFU-bibliotekerne ikke måtte lades i stikken. Dette emne var sammen med spørgsmålet om det hedder én eller ét katalog det gennemgående i tingets debat.

Den hidtidige statslige finansiering af bibliotek.dk, katalogiseringsbidrag for de statslige biblioteker, tilskud til de statslige bibliotekers DanBib-betaling og DBCs nationalbibliografiske opgaver er overgået til kommunerne ved at de tilhørende finanslovsbevillinger er overført til bloktilskud til kommunerne. Derudover er der overflyttet et beløb svarende til Det Kgl. Biblioteks betaling for DanBib til bloktilskuddet, hvilket modsvares af at biblioteket fremover ikke skal betale. De øvrige FFU-biblioteker skal fortsat betale et DanBib-abonnement på uændret niveau. Den praktiske udmøntning af disse nu kommunale opgaver er overladt til DBC med KOMBIT, kommunernes it-fællesskab som bestiller. Der er indgået en femårig aftale mellem DBC og KOMBIT. Det er i forvejen Kombit, som står for styring af folkebibliotekernes FBS (Fælles Bibliotekssystem). Dog har Slots- og Kulturstyrelsen fortsat ansvaret for reglerne for nationalbibliografien.

På denne måde samles bestilleropgaverne for alle DBCs store opgaver hos én organisation. Bestilleropgaven for DanBib og bibliotek.dk med tilhørende infrastruktur hidtil har været placeret i DDB (Danskernes Digitale Bibliotek), mens Slots- og Kulturstyrelsen hidtidig har haft ansvaret for de nationalbibliografiske opgaver, som DBC udfører. Bibliotekskatalogiseringen har hidtil været et rent DBC salgsprodukt primært til folkebibliotekerne, hvor Slotsog Kulturstyrelsen har stået for aftale og betaling gældende for de statslige biblioteker. KOMBIT har navngivet denne samlede opgaveportefølje Fælles

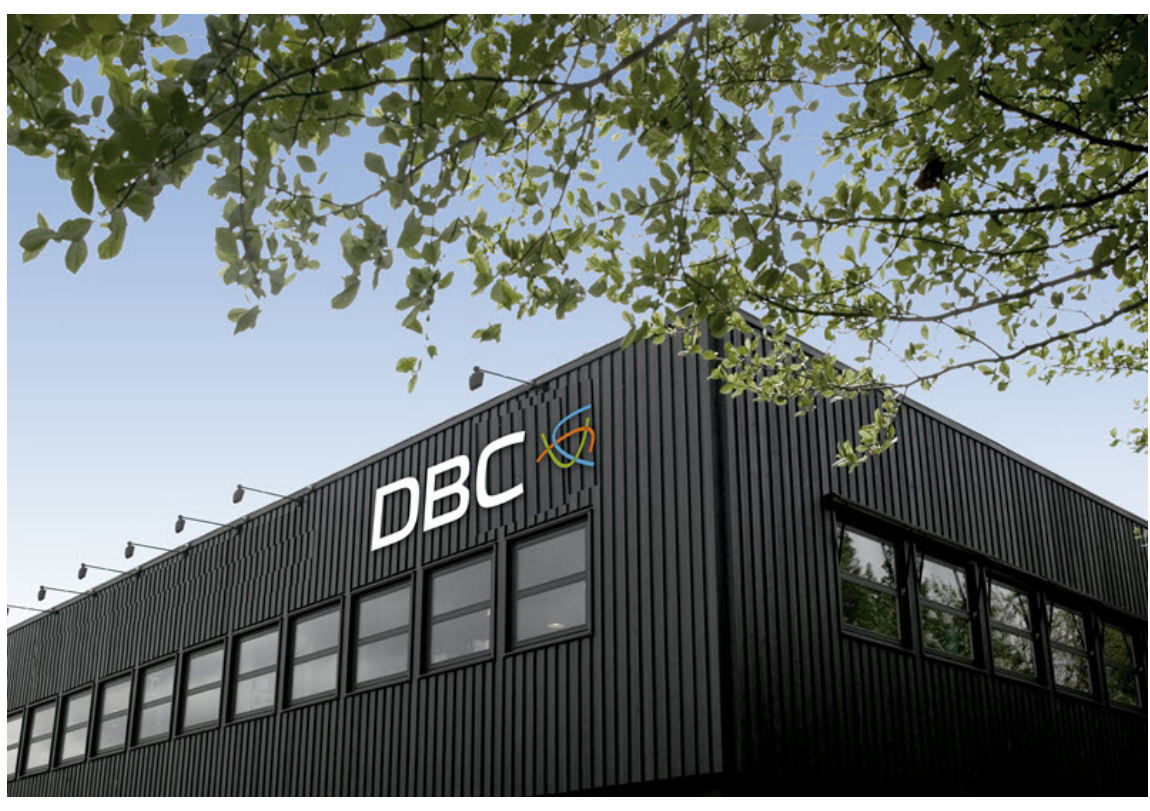

Biblioteksinfrastruktur (FBI). Sammen med folkebibliotekernes Fælles Bibliotekssystem (FBS) Bibliotekernes Data og It (DBI).

\section{Organiseringen}

Der er etableret en større organisering omkring varetagelsen af Bibliotekernes Data og It. Der er nedsat en styregruppe (SG), som træffer de strategiske beslutninger. Under SG er nedsat Porteføljegruppen, der yder sparring og rådgivning til styregruppen for BDI og KOMBIT om digital strategi og porteføljestyring for biblioteksområdet.

Næste trin ned af pyramiden er Prioriteringsudvalget, som yder forretningsmæssig sparring til KOMBIT, godkender ændring, videreudvikling og prioritering af den eksisterende portefølje og sikrer, at prioriterede ændringer er forankret i SGs strategiske beslutninger for BDI.

Specifikt for den fælles biblioteksinfrastruktur er nedsat FBI faggruppen. Faggruppen yder faglig rådgivning/ sparring til KOMBIT og kvalitetssikrer, foreslår prioriteringer og indstiller ændringsønsker til FBI.

KOMBIT har det forretningsmæssige ansvar for DBCs nationalbibliografiske opgaver, mens ansvaret for regler forsat er hos Slots- og Kulturstyrel- sen. SLKS har med udgangen af 2019 nedlagt Bibliografisk Råd (BIR). Det er hensigten fremover at SLKS støtter sig til et Nationalbibliografisk Udvalg (NBU) i forbindelse med varetagelse af regler for nationalbibliografien inkl. katalogiseringsregler og format. NBU er endnu ikke nedsat. KOMBIT nedsætter et rådgivende udvalg for Supplerende Biblioteksdata.

KOMBIT har valgt at varetage bestilleropgaven for FBI i tæt sammenhæng med bestilleropgaven for FBS. De strategiske og taktiske lag er fælles for FBI og FBS, men det operationelle lag er delt op.

Til at dække KOMBITs ressourceforbrug i forbindelse med opgaverne i FBI er der afsat en årlig ramme på 5 mio. kr.

Denne organisering er under etablering, hvilket naturligvis er blevet noget hæmmet af corona-krisen. Styregruppen nåede at holde sit første møde på normal vis. I skrivende stund har Prioriteringsudvalget og FBI Faggruppen holdt sine første "sættemøder" virtuelt. Det er derfor for tidligt at give en egentlig vurdering af KOMBIT organisering og opgavevaretagelse på om- 


\section{FFU-medlemmer i KOMBITs organisering}

\section{Styregruppen:}

- Erik Hoffmeister, Det Kgl. Bibliotek

Porteføljegruppen:

- Peter Rubeck Olesen, Professionshøjskolen UCN

- Bertil Dorch, Syddansk Universitetsbibliotek

Prioriteringsudvalget

- Per Steen Hansen, VIA Bibliotekerne

- Simone Schipp von Branitz Nielsen, Syddansk Universitetsbibliotek

\section{FBI Faggruppe}

- Eli Greve, Syddansk Universitetsbibliotek

- Leif Andresen, Det Kgl. Bibliotek

Udvalg for Supplerende BiblioteksData (SBD) (er endnu ikke nedsat)

- En repræsentant fra FFU'erne

Alle medlemmer, formål, kommissorier, referater: https://kombit.dk/BDlorganisering

rådet. Men både fra forberedelserne i 2019 og fra de nævnte første møder er det vores vurdering, at KOMBIT er klart opmærksom på at opgaven er noget andet end de rent kommunale opgaver, som KOMBIT ellers varetager - og er indstillet på at FFU-bibliotekerne også skal tilgodeses.

KOMBIT har udgivet et nyhedsbrev for FBS, hvor de sidste også har indeholdt informationer relevant for FFU-bibliotekerne. KOMBIT har ikke endnu fundet den endelig model for kommunikation rettet mod FFU-bibliotekerne.

Hvad der sker med resten af DDB? Efter beslutningen om at flytte bestillerfunktionen for DanBib og bibliotek fra DDB til Kombit blev taget i foråret 2019, var det oplagt at der skulle ske noget med DDB. På den baggrund nedsatte KL og Kulturministeriet en arbejdsgruppe med repræsentation fra folkebibliotekerne, der skulle anbefale fremtidsscenarier for DDB. Pga. af folketingets blev arbejdsgruppen sat i stå og først sidst i 2019 blev arbejdet revitaliseret. Resultatet er, at DDB nedlægges i sin nuværende form, og at opgaverne i stedet varetages af en ny forening etableret af folkebiblio- tekerne. DDB's sekretariat bliver overdraget til foreningen, som fremover skal stå for driften af en række digitale løsninger som fx folkebibliotekernes DDB CMS, biblioteks-app'en og digitale services. Den kommende forening vil være finansieret af kommunale midler. De statslige midler, der hidtil har været tildelt DDB, vil fremover indgå i den samlede statslige udviklingspulje til folkebiblioteksområdet, som samtidig vil få en ny struktur med øget dialog med KL og kommunerne og en stærkere faglig rolle til folkebibliotekerne.

\section{Håndtering i FFU-regi}

I forbindelse med DDBs overtagelse af DanBib og bibliotek blev nedsat FFUs DDB kontaktgruppe med repræsentanter for nogle af FC-bibliotekerne og repræsentanter for de øvrige organisationer på FFU-området. I forbindelse med omlægningen er gruppen omdøbt til FFU's Kontaktgruppe for Biblioteksinfrastruktur. Kontaktgruppen har stået for koordinering af høringssvar på de årlige udviklingsplaner og de senere år for et fælles høringssvar. Det vil fortsat være i regi af kontaktgruppen at arbejdet i relation til den fælles biblioteksinfrastruktur vil blive varetaget. Det vil nu ske i forhold til en større organi-
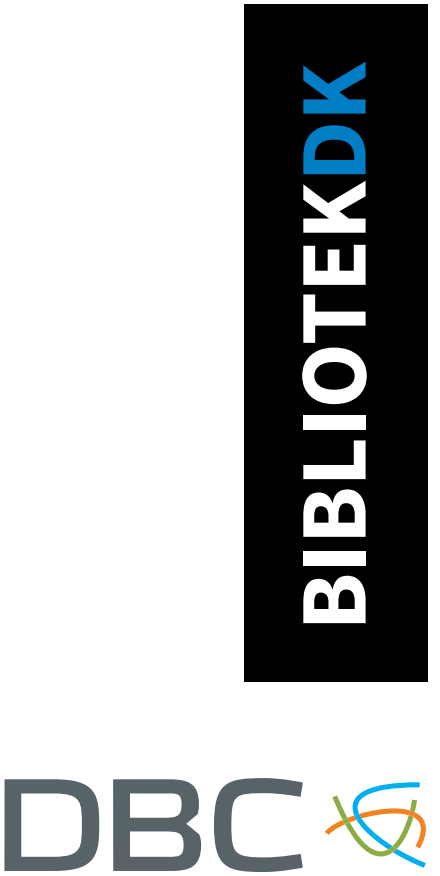

AET VIDEN FRI 
